\title{
Coronary artery disease in Asians in Birmingham
}

\author{
PATRICIA J LOWRY, DAVID R GLOVER, PETER J E MACE, WILLIAM A LITTLER \\ From the Department of Cardiovascular Medicine, University of Birmingham and East Birmingham Hospital, \\ Birmingham
}

SUMMARY The severity and pattern of coronary artery disease in patients referred for investigation of the disease was compared between Asian and white patients living in Birmingham, matched for age, sex, blood pressure, and duration of symptoms, to investigate the clinical impression that Asians have worse, in particular worse distal, coronary artery disease than whites. Risk factors and outcome were also examined. The coronary angiograms of 34 Asians were compared blindly and repeatedly with those of 68 whites by two independent observers. Coronary artery disease was found to be quantitatively more severe in Asians, but the distribution of the disease was the same. Some risk factors were significantly different: fewer Asians were smokers; fasting cholesterol concentrations were higher in whites; and whites were heavier, with a larger body surface area. Follow up data showed that more Asians were refused coronary artery bypass surgery because of the severity of their disease.

The incidence of coronary artery disease in immigrant Asian populations exceeds that in Asians remaining in their native country and also that in the indigenous population of their country of adoption. ${ }^{2} \mathrm{~A}$ higher prevalence of coronary artery disease is associated with higher serum cholesterol concentrations, especially higher concentrations of low density lipoproteins and lower concentrations of high density lipoproteins. ${ }^{3}$ It was our clinical impression that coronary artery disease in Asians living in Birmingham was more severe, particularly in the distal vessels, than in the indigenous white population, and we therefore assessed this objectively.

\section{Patients and methods}

A consecutive series of 36 Asian patients with coronary artery disease had been studied by coronary angiography in our laboratory from June 1976 to December 1982. Two had to be excluded because the cineangiograms had been lost. The remaining 34 patients were matched with 68 white patients with coronary artery disease who had been studied over the same period; each Asian was matched with two whites

Requests for reprints to Professor W A Littler, Department of Cardiovascular Medicine, East Birmingham Hospital, Bordesley Green East, Birmingham B9 5ST.

Accepted for publication 17 July 1984 for age, sex, blood pressure, and duration of symptoms to counteract different patterns of referral (Table 1). These Asian patients had been resident in the United Kingdom for a mean of over 13 (range $0.5-26)$ years. For 21 patients their country of origin was Pakistan, for seven East Africa, for three Bangladesh, for two India, and for one Afghanistan. Twenty nine patients were Moslem, three were Sikh, one was Hindu, and one Christian. Table 1 shows the social class ${ }^{4}$ of Asians and whites, obtained from hospital records. There was a significant difference in social class distribution between the two patient populations.

Coronary angiography is undertaken in our unit to assess suitability for surgery of known coronary artery disease and for diagnostic purposes. During the study

Table 1 Details of two groups of patients

\begin{tabular}{|c|c|c|c|}
\hline & $\underset{(n=34)}{\text { Asian }}$ & $\begin{array}{l}\text { White } \\
(n=68)\end{array}$ & $\begin{array}{l}p \\
\text { value }\end{array}$ \\
\hline $\begin{array}{l}\text { No of women } \\
\text { Mean (SD) age (years) } \\
\text { Mean (SD) blood pressure } \\
\text { (mm Hg) }\end{array}$ & $\begin{array}{l}3 \\
49 \cdot 1(7 \cdot 9) \\
120(15) \\
76(12)\end{array}$ & $\begin{array}{l}6 \\
49 \cdot 9(7 \cdot 5) \\
122(16) \\
75(9)\end{array}$ & $\begin{array}{l}\text { NS } \\
\text { NS }\end{array}$ \\
\hline $\begin{array}{l}\text { Mean (SD) duration of } \\
\text { symptoms (years) } \\
\text { No }(\%) \text { from social class }\end{array}$ & $3.2(3.6)$ & $3.2(3.8)$ & NS \\
\hline $\begin{array}{l}\text { II } \\
\text { III } \\
\text { IV } \\
\text { V }\end{array}$ & $\begin{array}{l}4(13) \\
16(47) \\
2(6) \\
12(34)\end{array}$ & $\left.\begin{array}{l}5(8) \\
14(20) \\
40(58) \\
2(3) \\
7(10)\end{array}\right\}$ & $<0.05$ \\
\hline
\end{tabular}


$29 \%$ of coronary angiograms performed in whites and $22 \%$ in Asians were normal. We compared the following risk factors for coronary artery disease: a positive family history in a first degree relative; a history of smoking; preceding hypertension; diabetes mellitus; and fasting cholesterol, triglyceride, and glucose concentrations measured on the morning of cardiac catheterisation.

Coronary angiography was performed by the standard Judkins's technique, ${ }^{5}$ with multiple projections taken of both right and left coronary arteries. Each cineangiogram was viewed blind on two separate occasions by two independent observers (PJL and WAL). The three major coronary arteries were examined for coronary artery disease and scored separately from 0 to 5 for proximal and distal disease (adapted from Humphries et al ${ }^{6}$ ). The score was an assessment of narrowing of the vessels: normal vessel scored 0 ; up to $25 \%$ narrowing, 1 ; up to $50 \%$ narrowing, 2; up to $75 \%$ narrowing, 3; subtotal occlusion or $95 \%$ narrowing, 4 ; and total occlusion, 5 . In the right coronary artery proximal was defined as the right coronary artery up to the origin of the posterior descending artery (if dominant), and the posterior descending artery and all other branches of the right coronary artery were defined as distal. The left main artery was scored separately: the left anterior descending artery was defined as proximal for the first two thirds of its course; the distal third and all other

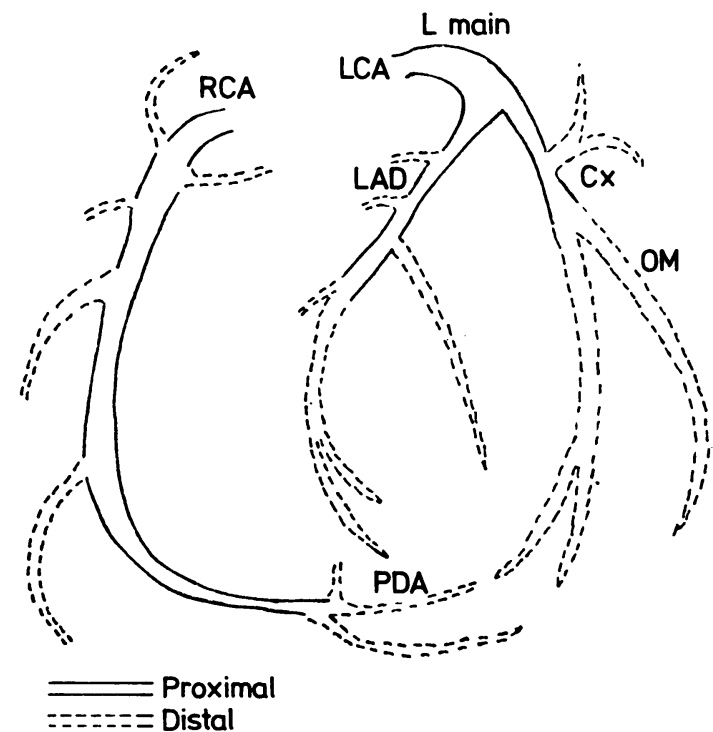

Diagrammatic representation of the coronary arterial tree. RCA, right coronary artery; $L C A$, left coronary artery; $P D A$, posterior descending artery; $L$ main, left main artery; $L A D$, left anterior descending artery; $C x$, circumflex artery; $O M$, obtuse marginal branch. branches were defined as distal. The left circumflex artery was defined as proximal up to the origin of the obtuse marginal artery; the obtuse marginal artery and the remainder of the circumflex artery were defined as distal (Fig). The scores for proximal, distal, and total disease and the number of diseased major vessels were then compared between the two groups.

Left ventricular function was assessed from the cineangiograms, noting the presence or absence of a left ventricular aneurysm and mitral regurgitation, and the calculation of the ejection fraction was done by a standard method based on volumes. ${ }^{7}$ The left ventricular end diastolic pressure was recorded at the time of catheterisation after the left ventricular angiogram. Standard 12 lead electrocardiograms recorded at the time of catheterisation were also compared between the two groups. Finally, the outcome for patients after catheterisation was compared, paying particular attention to the suitability of patients for coronary artery bypass surgery and the results of operation.

Results are expressed as the mean and one standard deviation. Differences between the whole groups were assessed by paired and unpaired Student's $t$ test. ${ }^{8}$ When subgroups were compared the $\chi^{2}$ test was used. $^{8}$

\section{Results}

\section{CORONARY ARTERY SCORES AND LEFT}

VENTRICULAR FUNCTION

The mean scores for proximal and distal disease did not differ significantly between the two groups of patients. There was, however, a trend for Asians to have more severe disease, and when the total scores were compared Asians had significantly higher scores than whites $(p<0.05)$. No significant differences were observed between the number of vessels diseased, and

Table 2 Coronary artery score and left ventricular function in two groups of patients. Values are mean (SD) except where indicated

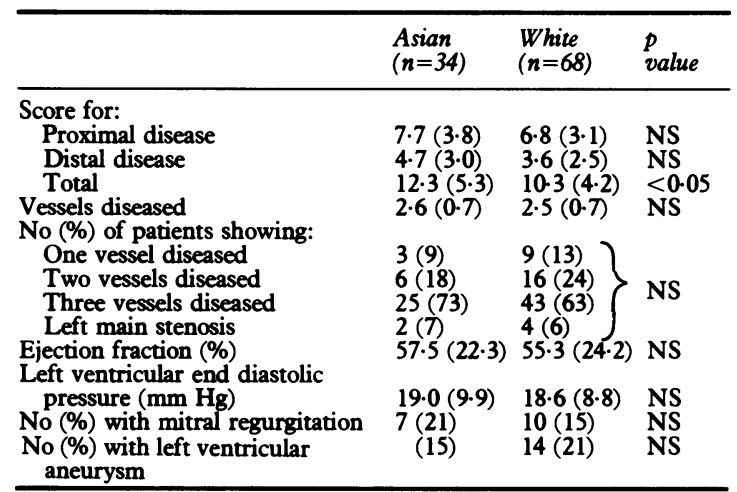


the pattern of disease was similar for the two groups. Left ventricular function did not differ significantly between the two groups (Table 2).

The scoring of the coronary artery lesions showed that the two independent observers did not differ significantly from each other when their individual scores were compared. The individual scores for proximal disease were $7.0(3.4)$ (WAL) $v 7.0(3.3)$ (PJL); for distal disease 4.0 (2.8) (WAL) v $3.9(2.8)$ (PJL); and for total disease $11.0(4.7)$ (WAL) $v$ 10.9 (4.7) (PJL). These figures are the mean for the whole group of patients, both Asian and white, for each observer.

Repeat viewing of the cineangiograms gave scores that did not differ significantly from each observers' initial score for proximal, distal, or total disease, indicating good reproducibility.

\section{RISK FACTORS}

Table 3 shows that there were significant differences between the two groups of patients for some risk factors. The Asians were more likely to be non-smokers $(p<0.005)$, but, if they were smokers, they were less likely to give up than the whites: eight Asian smokers (35\%) had given up compared with 41 whites $(66 \%)$. Fasting cholesterol concentrations were higher in whites, and whites were slightly heavier with a correspondingly greater body mass index.

\section{ELECTROCARDIOGRAMS}

No significant differences were observed in the electrocardiograms: they were normal in $12(35 \%)$ of the Asians and showed evidence of previous transmural

Table 3 Risk factors for coronary artery disease in two groups of patients

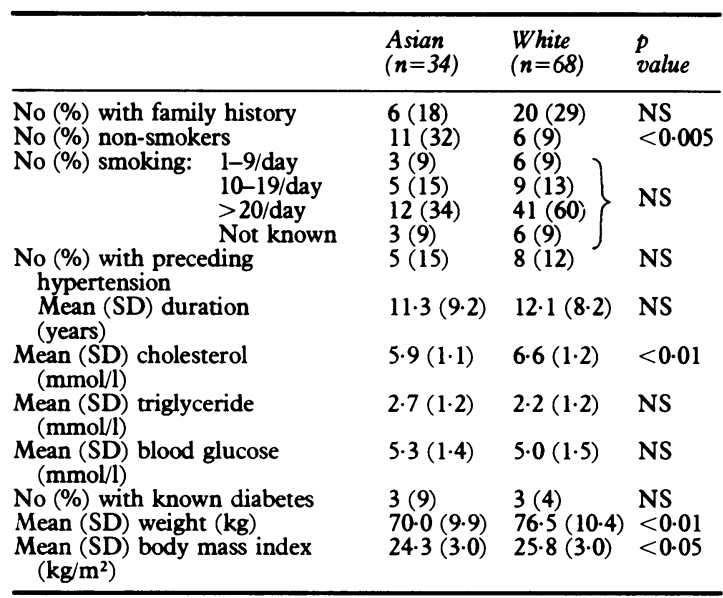

Conversion: SI to traditional units-Cholesterol: $1 \mathrm{mmol} / \mathrm{l} \approx 39 \mathrm{mg}$ $100 \mathrm{ml}$. Triglyceride: $1 \mathrm{mmol} / \mathrm{l} \approx 88.6 \mathrm{mg} / 100 \mathrm{ml}$. Glucose: $1 \mathrm{mmol} /$ $1 \approx 18 \mathrm{mg} / 100 \mathrm{ml}$.
Table 4 No(\%) of patients in two groups offered or not offered surgery, together with reason for decision

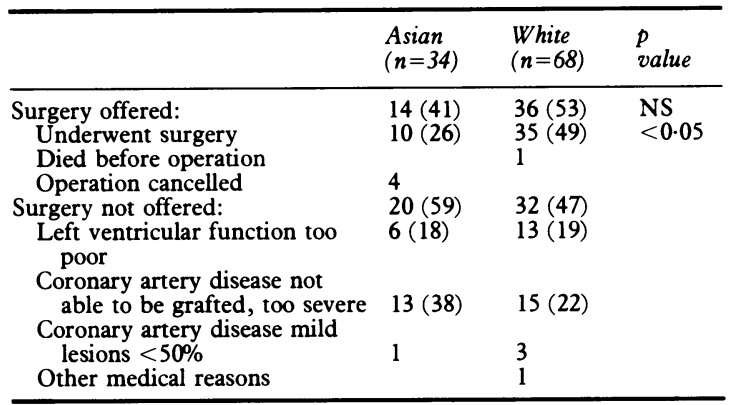

infarction in 17 (50\%), whereas they were normal in $20(25 \%)$ of the whites and showed evidence of previous transmural infarction in 37 (54\%).

\section{SURGERY}

Table 4 shows the details of patients who were or were not offered surgery. There was no significant difference in the percentage of patients offered or refused surgery. Significantly $(p<0.05)$ more whites, however, underwent surgery; this difference occurred because four Asian patients had their operation cancelled. In two Asians this was a medical decision prompted by great symptomatic improvement; in the other two operation was refused by the patients themselves when they were due for surgical admission. All 10 Asians who underwent surgery had coronary artery bypass grafts alone. Thirty one whites had coronary artery bypass grafts alone, three had additional resection of left ventricular aneurysm, and one had resection of left ventricular aneurysm alone. The mean number of grafts per patient was 2.55 for Asians compared with 2.35 for whites.

At catheterisation after coronary artery bypass surgery the graft patency rate was $71 \%$ for Asians compared with $77 \%$ for whites. More Asian than white patients were not offered surgery because of the severity and pattern of their coronary artery disease.

\section{FOLLOW UP AND OUTCOME}

The mean (SD) duration of follow up after catheterisation was 19.6(16.7) months for Asians compared with 22.1(14.0) months for whites. Five Asians and five whites subsequently died. Of the Asians, four who died had been refused operation. Of these four, three died of left ventricular failure and one of acute myocardial infarction. The remaining Asian who died did so suddenly four months after surgery. Of the whites who died, one died while awaiting admission for surgery, one died during operation, one died suddenly eight months after surgery, and two who were refused operation died of left ventricular failure. 


\section{Discussion}

The main finding of this study was that coronary artery disease in Asians was quantitatively more severe than in whites. There was, however, no difference in pattern of the disease. Significant differences in risk factors emerged: Asians were more likely to be non-smokers (but, if smokers, were less likely to give up), to have lower cholesterol concentrations, and to weigh less than whites.

Why should Asians have worse coronary artery disease than whites? It cannot simply be due to later referral since the patients were matched for duration of symptoms. Our indications for angiography were exactly the same in both groups, and we found the same proportion of whites and Asians examined to have coronary artery disease. Thus the observed differences in coronary artery disease were not due to a higher threshold for investigation in Asians.

Coronary angiography is essential in establishing the extent and severity of coronary artery disease during life. The measurement of coronary artery lesions by angiography is a crude and subjective assessment, and accurate evaluation of lesions is aided by good radiographic technique, the use of different projections of the vessels, and -careful attention to anterograde or retrograde filling of vessels beyond an obstruction. Assessment of a proximal narrowing tends to be more accurate than that of a distal lesion, especially where there is high grade proximal disease. ${ }^{9}$ We assessed our films blind, independently, and repeatedly, and obtained good observer agreement. We thus believe the observed differences to be real and unbiased.

Although the incidence of and risk factors for coronary artery disease have been well documented for white populations, the rules cannot necessarily be applied to all races and cultures ${ }^{10^{-12}}$; indeed, differences in risk factors between ethnic groups are known to occur. ${ }^{1314}$ Most Asians in Birmingham come from Pakistan, and most are Moslem; they have been resident in this country for several years but their culture has not altered greatly; their dietary and smoking habits are different from those of the white population. Not surprisingly, therefore, their risk factors for coronary artery disease are different. Also, differences within the Asian populations are to be expected as the term Asian encompasses different ethnic and cultural groups and, in particular, different religious practices, which may influence greatly the composition of the diet. Our hospital dietician tells us that our Asian patients eat a largely vegetarian diet and that a large amount of ghee (clarified butter) is used in its preparation. These facts may explain in part why results of tests for cholesterol concentrations differ, as various studies have examined different populations. ${ }^{23}$
Because of the retrospective nature of this study, details are not available of the ratio of low density to high density lipoproteins in our patients.

The follow up of patients in this study shows that a similar proportion were offered coronary surgery but significantly fewer Asians underwent operation. More Asians were unsuitable for coronary artery bypass grafting, reflecting the finding that coronary artery disease was more severe in Asians than in whites and, not surprisingly, four of this group died subsequently as a result of their coronary artery disease.

Further, and more detailed, study of risk factors in different ethnic groups is obviously required, but in the meantime our study suggests that Asian patients with coronary artery disease should be investigated early if they are to benefit from coronary artery surgery.

We thank Dr C J Bulpitt for advice in preparing the report and Mr T J Stallard for the statistical analysis of the results. We are grateful to the Medical Services Study Group of the Royal College of Physicians, London, for financial help. PJL was receiving a British Heart Foundation research grant. WAL is a Wolfson research fellow of the Royal College of Physicians.

\section{References}

1 Pedoe HT, Clayton D, Morris JN, Brigden W, McDonald L. Coronary heart-attacks in East London. Lancet 1975; ii: 833-8.

2 Miller GJ, Beckles GLA, Alexis SD, Byam NTA, Price SGL. Serum lipoproteins and susceptibility of men of Indian descent to coronary heart disease. Lancet 1982; ii: 200-3.

3 Shaper AG, Jones KW. Serum-cholesterol, diet, and coronary heart disease in Africans and Asians in Uganda. Lancet 1959; ii: 534-7.

4 Benjamin B. Health and vital statistics. London: George Allen and Unwin, 1968.

5 Judkins MP. Selective coronary arteriography. I. A percutaneous transfemoral technic. Radiology 1967; 89: 815-24.

6 Humphries JO, Kuller L, Ross RS, Friesinger GC, Page EE. Natural history of ischemic heart disease in relation to arteriographic findings. Circulation 1974; 49: 489-97.

7 Rackley CE. Quantitative evaluation of left ventricular function by radiographic techniques. Circulation 1976; 54: 862-79.

8 Snedecor GW, Cochran WG. Statistical methods. 6th ed. Ames: Iowa State University Press, 1967.

9 Rösch J, Dotter CT, Antonovic R, Bonchek L, Starr A. Angiographic appraisal of distal vessel suitability for aortocoronary bypass graft surgery. Circulation 1973; 48: 202-12.

10 Gillum RF. Coronary heart disease in black populations. I. Mortality and morbidity. Am Heart $\mathcal{f}$ 1982; 104: 839-51.

11 Gillum RF, Grant CT. Coronary heart disease in black populations. II. Risk factors. Am Heart $\mathcal{f}$ 1982; 104: 852-64.

12 Walker ARP. Extremes of coronary heart disease mortality in ethnic groups in Johannesburg, South Africa. Am Heart $\mathcal{F}$ 1963; 66: 293-5.

13 Beevers DG, Cruickshank JK. Age, sex, ethnic origin and hospital admission for heart attack and stroke. Postgrad Med $\mathcal{F}$ 1981; 57: 763-5.

14 Eisenberg S, Ehrenfeld M, Friedman G, Friedlander Y. Risk factors for coronary artery disease in patients with acute myocardial infarction. Israel f Med Sci 1981; 17: 309-17. 